\title{
Synthesis of Novel Chiral Poly(methacrylate)s Having Urea Moieties and $(S)$-Methylbenzyl or L-Phenylalanine Methyl Ester Groups and Their Chiral Recognition Abilities
}

\author{
Yong-Kyung LeE, Nobuo Hisamitsu, Kenjiro Onimura, \\ Hiromori TsuTsumI, and Tsutomu OisHI ${ }^{\dagger}$ \\ Department of Applied Chemistry and Chemical Engineering, Faculty of Engineering, Yamaguchi \\ University, 2-16-1 Tokiwadai, Ube, Yamaguchi 755-8611, Japan
}

(Received August 13, 2001; Accepted November 7, 2001)

\begin{abstract}
New chiral methacrylates, $(S)$-methylbenzyl methacryloyloxyethyl urea (MBMOU) and $(S)$ methoxycarbonylbenzylmethyl methacryloyloxyethyl urea (MCMOU) were synthesized from 2-(methacryloyloxy)ethyl isocyanate $(\mathrm{MOI})$ and $(S)$-methylbenzylamine and L-phenylalanine methyl ester, respectively. Radical polymerizations of MBMOU and MCMOU were performed under several conditions to obtain the corresponding polymers whose specific optical rotations $\left([\alpha]_{435}^{25}\right.$ ) were $-13.5^{\circ}$ to $-10.9^{\circ}$ and $30.8^{\circ}$ to $31.5^{\circ}$, respectively. From the results of radical copolymerizations of RMOU (MBMOU and MCMOU, $\mathrm{M}_{1}$ ) with styrene $\left(\mathrm{ST}, \mathrm{M}_{2}\right)$ or butyl methacrylate $\left(\mathrm{BMA}, \mathrm{M}_{2}\right)$, monomer reactivity ratios $\left(r_{1}, r_{2}\right)$ and Alfrey-Price $Q-e$ were determined. The chiroptical properties of poly(MBMOU-co-M $\left.\mathrm{M}_{2}\right) \mathrm{s}$ were strongly influenced by $c o$-units. Poly(RMOU)-bonded-silica gel as chiral stationary phase (CSP) was prepared for high performance liquid chromatography (HPLC). The CSPs resolved some racemates such as ketoprofen and ethyl mandelate. The enantiorecognition ability may be based on higher-ordered structures of the polymer.

KEY WORDS 2-(Methacryloyloxy)ethyl isocyanate / Radical Polymerization / Monomer Reactivity Ratios / Chiral Stationary Phase / Optical Resolution /
\end{abstract}

2-(Methacryloyloxy)ethyl isocyanate (MOI) is a bifunctional monomer with both a reactive isocyanate group and a polymerizable double bond, and is convenient and widely used for crosslinking agents and materials for molecular design of new polymers. ${ }^{1}$ Many kinds of MOI derivatives have been synthesized from several alcohol and amine compounds and polymerized. ${ }^{2}$ MOI is also useful for preparation of macromonomer. ${ }^{3}$ We synthesized and polymerized $N$ substituted maleimide (RMI) macromonomers and examined from the view point of thermal stability of the polymers obtained. ${ }^{4}$ However there have been few reports on synthesis of MOI derivatives bearing an optically active group. Bamford et al. ${ }^{5}$ synthesized MOI derivatives from $\alpha$-amino acid and D-glucosamine, and examined applications of the polymers to blood compatibility. Chiral stationary phase (CSP) for high performance liquid chromatography (HPLC) was prepared from MOI and cyclodextrin. ${ }^{6}$ To our knowledge, no chiroptical properties of MOI derivatives with optically active groups have been reported. Thus, we lately reported on synthesis and polymerizations of some chiral methacryloyloxyethyl carbamates (RMOC) from MOI and chiral alcohols such as cholesterol, L-menthol, amino acid derivatives, and 2-hydroxy-2'-methoxy$1,1^{\prime}$-binaphthalene, and chiroptical properties of the polymers. $^{7-9}$

Recently, a wide variety of CSPs have been developed for the separation of enantiomers by HPLC. ${ }^{10}$ Although many kinds of synthetic chiral polymers have been applied to the CSPs, there have been few reports on preparation of CSPs for HPLC from poly(methacrylate)s bearing a chiral pendant group. ${ }^{11}$ The reason may be that low chiral recognition ability of the chiral pendant group used and/or the absence of stable higher-ordered structures of the polymers. ${ }^{11}$ Liu et al. ${ }^{12}$ reported on optical resolution of racemates by chiral poly(methacrylate) having (+)-5oxobornyl moieties. Tamai and Miyano et al. ${ }^{13}$ synthesized optically active poly(methacrylate)s bearing a $1,1^{\prime}$-binaphthalene moiety as pendant group, and investigated on optical resolution ability as a chiral adsorbent for HPLC. However, the chiral recognition ability of the polymers was not conferred by higher-ordered structures of the polymer, but mainly interaction between the individual $1,1^{\prime}$-binaphthalene units and the racemates. ${ }^{13}$ It is well known that poly(methacrylamide)s bearing a chiral pendant group are served as CSPs with outstanding recognition ability due to conformation controlled by hydrogen bonds between amide groups. Blaschke et al. ${ }^{14}$ and Arlt et al. ${ }^{15}$ reported the synthesis of many chiral poly(methacrylamide)s from $\alpha$-amino

†To whom all correspondence should be addressed (Tel: +81-836-85-9281, Fax: +81-836-85-9201, E-mail: oishi@po.cc.yamaguchiu.ac.jp). 


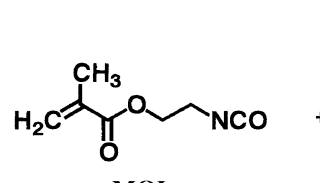

MOI<smiles>C=C(C)C(=O)OCCNC(C)=O</smiles>

MOI

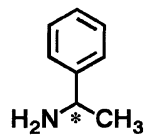

$S$-(-)-Methyl benzyl a mine

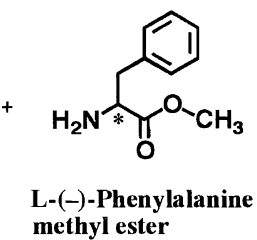

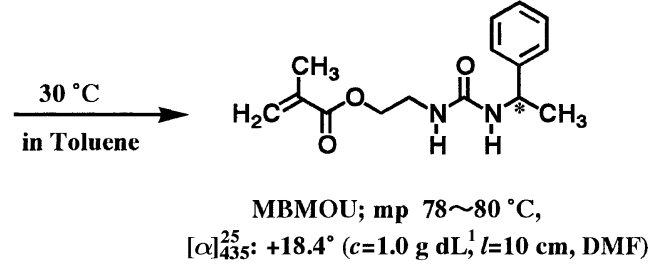

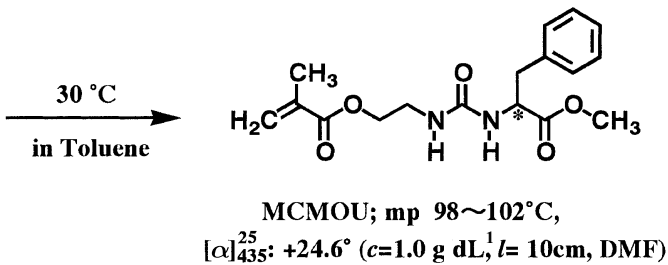

Scheme 1.

acids or chiral amines and their chiral recognition abilities. We reported previously on preparations of new CSPs with poly(RMOC) and their chiral recognition abilities by HPLC. ${ }^{8,9}$

This article describes the synthesis and polymerization of two new chiral methacryloyloxyethyl urea (RMOU) from MOI and chiral amines such as $(S)-(-)$-methylbenzyl amine and L-(-)-phenylalanine methyl ester. Radical homopolymerizability of RMOU, copolymerizability with styrene (ST) or butyl methacrylate (BMA), and chiroptical properties of the homo- and copolymers obtained are discussed. CSPs are prepared from silica gel and the chiral polymethacrylate for HPLC and their optical resolution abilities are also investigated.

\section{EXPERIMENTAL}

\section{Materials}

ST and BMA were purified by the ordinary methods. ${ }^{16}$ Tetrahydrofuran (THF), benzene, and toluene were dried over sodium metal and then used after distillation. $\quad N, N$-Dimethylformamide (DMF), dichloromethane $\left(\mathrm{CH}_{2} \mathrm{Cl}_{2}\right)$, and chloroform $\left(\mathrm{CH}_{3} \mathrm{Cl}\right)$ were used after distillation. 2,2'-Azobisisobutyronitrile (AIBN) was purified by recrystallization from methanol. Other reagents were used without further purification. Monomers of RMOU were synthesized, as drawn in Scheme 1.

(S)-Methylbenzyl methacryloyloxyethyl urea (MB$M O U)$. A solution of MOI $\left(2.0 \mathrm{~g}, 1.3 \times 10^{-2} \mathrm{~mol}\right)$ in toluene $(25 \mathrm{~mL})$ was added dropwise to a stirred solution of $(S)$-(-)-methylbenzyl amine $\left(1.6 \mathrm{~g}, 1.3 \times 10^{-2}\right.$ $\mathrm{mol})$ in toluene $(25 \mathrm{~mL})$ under nitrogen at room temperature. The solution was heated at $35^{\circ} \mathrm{C}$ and stirred for $24 \mathrm{~h}$ under nitrogen. The reaction mixture was evaporated under reduced pressure to give the crude product and washed with diethyl ether. Purification by recrystallization from water/methanol (1/1) gave MBMOU as white powder: yield $48.8 \%$; $\mathrm{mp} 78-80^{\circ} \mathrm{C}$; $[\alpha]_{435}^{25}+18.4^{\circ}\left(c=1.0 \mathrm{~g} \mathrm{dL}^{-1}, l=10 \mathrm{~cm}, \mathrm{DMF}\right) ;{ }^{1} \mathrm{H}$ NMR $\left(\delta\right.$, ppm from TMS in $\left.\mathrm{CDCl}_{3}\right) 7.33-7.20(\mathrm{~m}$, $5 \mathrm{H}$, in phenyl groups), 6.03 (s, $1 \mathrm{H}$, (trans) $\mathrm{CH}_{2}=\mathrm{C}$ ), $5.54\left(\mathrm{~s}, 1 \mathrm{H},(\right.$ cis $\left.) \mathrm{CH}_{2}=\mathrm{C}\right), 5.23\left(\mathrm{bs}, 1 \mathrm{H}, \mathrm{C}^{*}-\mathrm{N}-\mathrm{H}\right)$, 5.02 (bs, $\left.1 \mathrm{H}, \mathrm{CH}_{2}-\mathrm{N}-\mathrm{H}\right), 4.78\left(\mathrm{~m}, 1 \mathrm{H}, \mathrm{C}^{*}-\mathrm{H}\right), 4.13-$ $4.09\left(\mathrm{t}, 2 \mathrm{H}, J=6.11\right.$ and 5.28, $\left.\mathrm{COOCH}_{2}\right), 3.46-3.39$ (m, $\left.2 \mathrm{H}, \underline{\mathrm{CH}}_{2} \mathrm{NH}\right), 1.89$ (s, $\left.3 \mathrm{H}, \mathrm{CH}_{2}=\mathrm{C}\left(\underline{\mathrm{CH}}_{3}\right)\right), 1.42-$ $1.39\left(\mathrm{~d}, 3 \mathrm{H}, J=6.93, \mathrm{C}^{*}-\mathrm{CH}_{3}\right) ;{ }^{13} \mathrm{C}-\mathrm{NMR}(\delta, \mathrm{ppm}$ from TMS in $\left.\mathrm{CDCl}_{3}\right)$ 167.85 (C=O), $158.10(\mathrm{NH}-\mathrm{CO})$, $144.61,129.10,127.63,126.23$ (in phenyl groups), $136.37(=\mathrm{C}<), 126.37 \quad\left(\mathrm{CH}_{2}=\right), 64.53 \quad\left(\mathrm{COOCH}_{2}\right)$, $50.57\left(\mathrm{NH}-\mathrm{C}^{*}\right), 39.73\left(\underline{\mathrm{CH}}_{2} \mathrm{NH}\right), 23.74\left(\mathrm{C}^{*}-\underline{\mathrm{C}} \mathrm{H}_{3}\right)$, $18.67\left(\mathrm{CH}_{2}=\mathrm{C}\left(\underline{\mathrm{CH}}_{3}\right)\right.$; Anal. Calcd for $\mathrm{C}_{15} \mathrm{H}_{20} \mathrm{~N}_{2} \mathrm{O}_{3}: \mathrm{C}$, 65.20 ; H, 7.30; N, 10.14; Found: C, 65.67; H, 7.61; N, 10.14 .

(S)-Methoxycarbonylbenzylmethyl methacryloyloxyethyl urea (MCMOU). L-(-)-Phenylalanine methyl ester was synthesized by the ordinary methods. ${ }^{17}$ MCMOU was synthesized from MOI and L-(-)phenylalanine methyl ester by the same procedure as that of the synthesis of MBMOU: yield $32.8 \%$; $\mathrm{mp} \quad 100-102^{\circ} \mathrm{C} ;[\alpha]_{435}^{25}+24.6^{\circ}\left(c=1.0 \mathrm{~g} \mathrm{dL}^{-1}\right.$, $l=10 \mathrm{~cm}, \mathrm{DMF}) ;{ }^{1} \mathrm{H}$ NMR $(\delta$, ppm from TMS in $\left.\mathrm{CDCl}_{3}\right)$ 7.32-7.09 (m, 5H, in phenyl groups), 6.12 (s, $1 \mathrm{H}$, (trans) $\mathrm{CH}_{2}=\mathrm{C}$ ), 5.58 (s, $1 \mathrm{H},($ cis $) \mathrm{CH}_{2}=\mathrm{C}$ ),

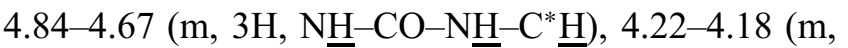
$\left.2 \mathrm{H}, \mathrm{COOCH}_{2}\right), 3.72\left(\mathrm{~s}, 3 \mathrm{H}, \mathrm{O}-\mathrm{CH}_{3}\right), 3.57-3.44(\mathrm{~m}$, $\left.2 \mathrm{H}, \mathrm{CH}_{2} \mathrm{NH}\right), 3.16-3.02\left(\mathrm{~m}, 2 \mathrm{H}, \mathrm{C}^{*}-\mathrm{CH}_{2}\right), 1.94(\mathrm{~s}$, $\left.3 \mathrm{H}, \mathrm{CH}_{2}=\mathrm{C}\left(\underline{\mathrm{CH}}_{3}\right)\right) ;{ }^{13} \mathrm{C}$ NMR $(\delta, \mathrm{ppm}$ from TMS in $\left.\mathrm{CDCl}_{3}\right) 173.06\left(\mathrm{C}^{*} \mathrm{H}-\underline{\mathrm{C}}=\mathrm{O}\right), 167.44(\mathrm{C}=\mathrm{O}), 156.78$ $(\mathrm{NH}-\mathrm{CO}), 136.12(=\mathrm{C}<), 136.00,129.31,128.50$, 127.01 (in phenyl groups), $126.02\left(\mathrm{CH}_{2}=\right), 64.03$ $\left(\mathrm{COOCH}_{2}\right), 53.98\left(\mathrm{O}-\mathrm{CH}_{3}\right), 52.24\left(\mathrm{NH}-\mathrm{C}^{*}\right), 39.55$ $\left(\underline{\mathrm{CH}}_{2} \mathrm{NH}\right), 38.44\left(\underline{\mathrm{CH}}_{2}-\mathrm{Ph}\right), 18.30 \quad\left(\mathrm{CH}_{2}=\mathrm{C}\left(\underline{\mathrm{CH}}_{3}\right)\right)$; 

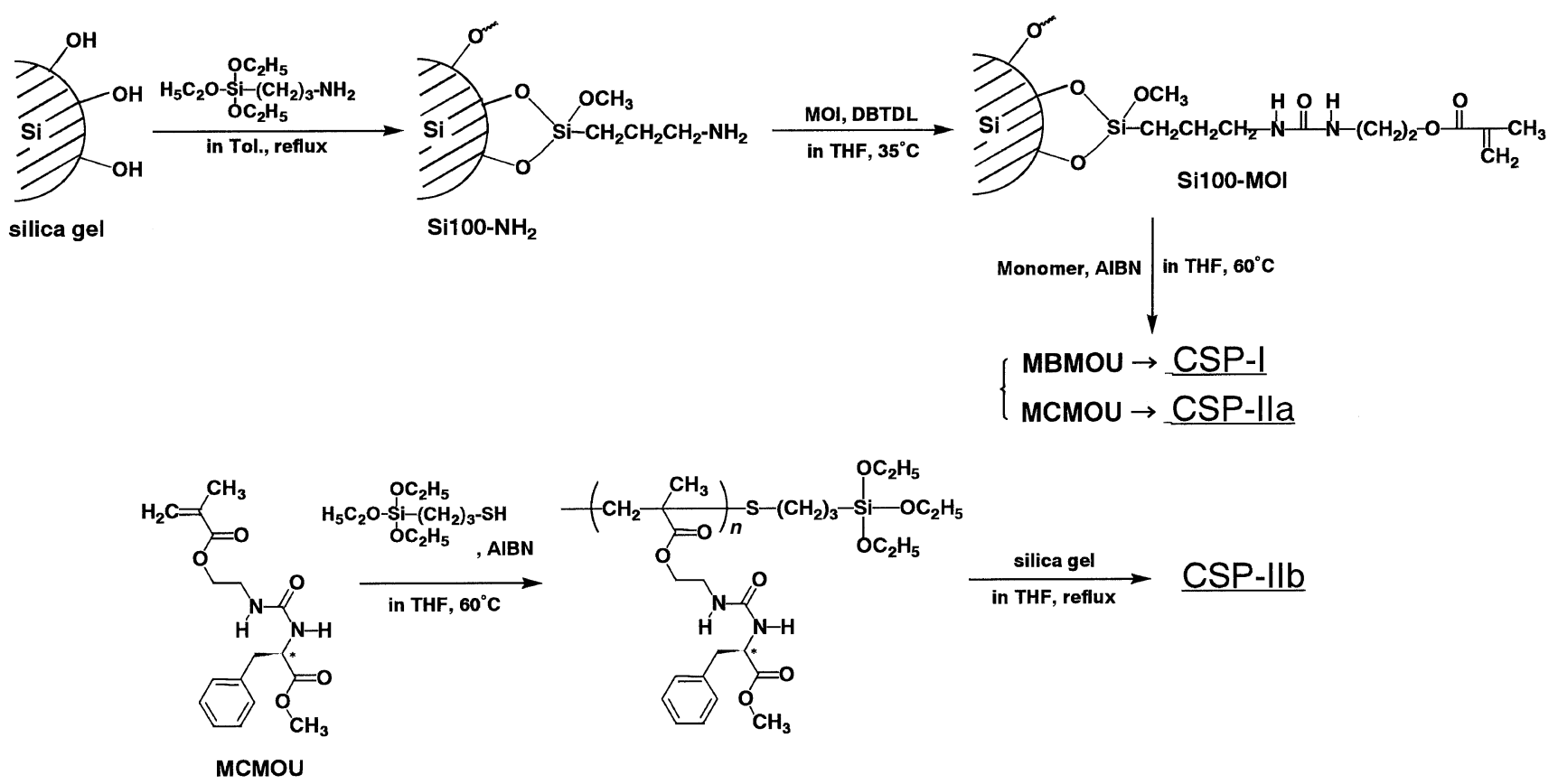

Scheme 2.

Anal. Calcd for $\mathrm{C}_{17} \mathrm{H}_{22} \mathrm{~N}_{2} \mathrm{O}_{5}: \mathrm{C}, 61.07 ; \mathrm{H}, 6.63 ; \mathrm{N}$, 8.38; Found: C, 61.14; H, 6.85; N, 8.40.

\section{Radical Polymerization}

Radical homopolymerizations and copolymerizations were performed with AIBN as initiator in suitable solvent in a sealed tube at $60^{\circ} \mathrm{C}$. After polymerization the polymer solution was poured into a large amount of methanol to precipitate the polymer. The obtained polymer was purified by reprecipitating it twice from the DMF solution to excess methanol. DMF insoluble polymer was washed with methanol. The polymers were decanted and dried in vacuum for 3 days. The composition of the copolymer was calculated by ${ }^{1} \mathrm{H}$ NMR spectra and elemental analysis $(\mathrm{N})$.

\section{Preparation of CSPs for HPLC and Column Packing}

Macroporous silica gel (TOSOH, TSK-GEL SI 100: mean particle size, $5 \mu \mathrm{m}$; pore size $100 \AA$ ) was silanized with 3-aminopropyl triethoxysilane according to the literature method. ${ }^{18}$ MOI $(16 \mathrm{~mL})$ was added to a slurry of the silanized silica gel $(8.0 \mathrm{~g})$ under nitrogen. The mixture was heated $35^{\circ} \mathrm{C}$, stirred for $45 \mathrm{~h}$ under nitrogen and then cooled to room temperature. The reaction mixture was filtered, washed with dichloromethane, acetone, and methanol, and then dried in vacuo to obtain silica gel containing vinyl groups in the surface (Si100-MOI in Scheme 2). Si100-MOI $(1.0 \mathrm{~g})$ and the monomer (MBMOU or MCMOU) $(0.5 \mathrm{~g})$ were weighed in a Shlenk's reaction tube. A solution of AIBN ( $3 \mathrm{~mol} \%$ against monomer) in THF $(10 \mathrm{~mL})$ was added to the mixture in a Shlenk's re- action tube under nitrogen. The slurry was shaken at $60^{\circ} \mathrm{C}$ for $48 \mathrm{~h}$ and cooled to room temperature. The reaction mixture was filtered, washed with THF, DMF, acetone and methanol, and then dried in vacuo to afford CSP-I (monomer $=$ MBMOU) and CSP-IIa (monomer $=\mathrm{MCMOU})$.

MCMOU $\left(0.5 \mathrm{~g}, 1.51 \times 10^{-3} \mathrm{~mol}\right)$ was radically polymerized with AIBN ( $5 \mathrm{~mol} \%$ against MCMOU) as initiator and 3-mercaptopropyl triethoxysilane $(10 \mathrm{~mol} \%$ against $\mathrm{MCMOU}$ ) as chain-transfer agent at $60^{\circ} \mathrm{C}$ in THF $(2 \mathrm{~mL})$ for $24 \mathrm{~h}$, and the polymerization solution was cooled at $0^{\circ} \mathrm{C}$. Macroporous silica gel $(1.0 \mathrm{~g})$ in THF $(10 \mathrm{~mL})$ was added to the solution, which was refluxed for $24 \mathrm{~h}$ and cooled at room temperature. The reaction mixture was filtered, washed with THF, DMF, acetone, and methanol, and dried in vacuo to afford CSP-IIb.

The contents ( $w t \%)$ of polymer segment on CSPI, CSP-IIa, and CSP-IIb were $32 \mathrm{wt} \%, 17 \mathrm{wt} \%$, and $11 \mathrm{wt} \%$, respectively, which were estimated from infrared (IR) spectra, according to the reported previously. ${ }^{8,9}$ The properties of polymer segment on CSP-IIb determined as follows: reduced viscosity $(\eta)=0.04 \mathrm{dL} \mathrm{g}^{-1}$ in DMF at $30^{\circ} \mathrm{C}$, number-averagemolecular weight $\left(M_{\mathrm{n}}\right)=1740$, polydispersity (weightaverage-molecular weight $\left.\left(M_{\mathrm{w}}\right) / M_{\mathrm{n}}\right)=2.46$, specific optical rotation $\left([\alpha]_{435}^{25}\right)=23.7^{\circ}$ in DMF. The CSPs were packed in a stainless steel HPLC column (i.d., $0.2 \mathrm{~mm}$; length, $15 \mathrm{~cm}$ ) by a slurry method. Theoretical plate numbers of the columns packed CSP-I, CSP-IIa, and CSP-IIb were 276, 346, and 1610, respectively, which were measured using toluene as standard 

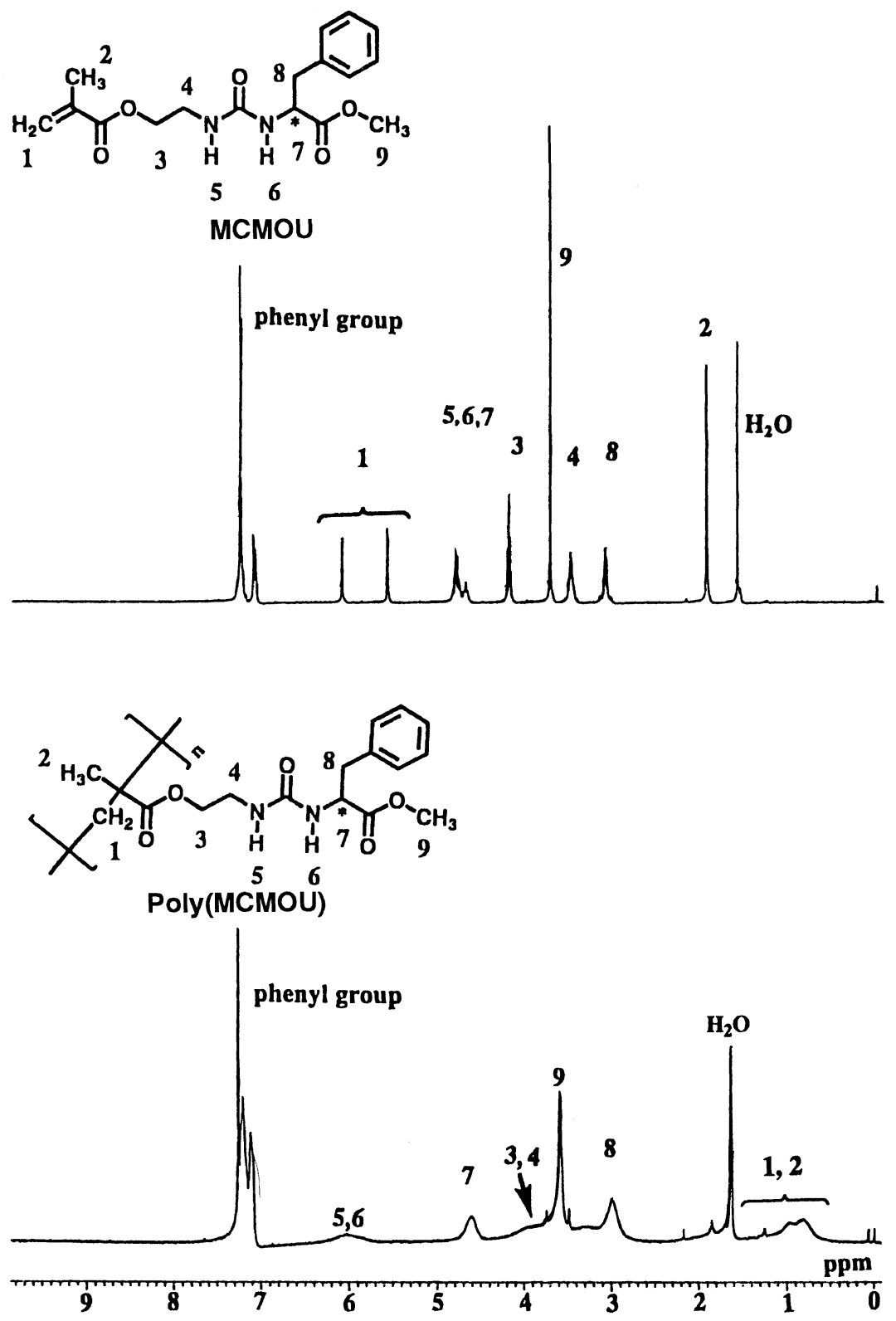

Figure 1. ${ }^{1} \mathrm{H}$ NMR spectra for $\mathrm{MCMOU}$ and poly(MCMOU) in $\mathrm{CDCl}_{3}$ at $23.5^{\circ} \mathrm{C}(270 \mathrm{MHz})$.

in methanol as eluent at a flow rate of $0.5 \mathrm{~mL} \mathrm{~min}-1$ at $25^{\circ} \mathrm{C}$.

\section{Measurements}

NMR spectra were recorded at $25^{\circ} \mathrm{C}$ using JEOL EX-270 (Jeol Ltd.). IR spectra were recorded using Shimadzu FT IR-8100A (Shimadzu Ltd.). Elemental analysis was carried out with a $\mathrm{CHN}$ recorder (Yanagimoto Co.). Gel permeation chromatography (GPC) measurements were carried out at $50^{\circ} \mathrm{C}$ using THF as an eluent on a Shimadzu SPD-10A (Shimadzu Ltd.) equipped with a UV detector, HSG-40, HSG-20, HSG15, and HSG-10 columns, and a Jasco-OR 990 (Japan Spectroscopic Co.) with a polarimetric detector. Specific optical rotations were measured with a Jasco DIP140 (5 and $10 \mathrm{~cm}$ quartz cell lengths, $c=1.0 \mathrm{~g} \mathrm{dL}^{-1}$ in
DMF). HPLC measurements were carried out on a Shimadzu LC-10AT (Shimadzu Ltd.) equipped with UV detection at $254 \mathrm{~nm}$.

\section{RESULTS AND DISCUSSION}

Radical Homopolymerizations of $M B M O U$ and $M C$ $M O U$

Radical homopolymerizations of MBMOU and MCMOU were performed with AIBN as initiator at $60^{\circ} \mathrm{C}$ in various solvents. The results are summarized in Table I. The polymerizations proceeded heterogeneously except in DMF. The obtained polymers were colorless powders, though sticky and rubbery state in methanol and $n$-hexane. Poly(MBMOU) and poly(MCMOU) were insoluble in organic solvents such as THF, ace- 
Table I. Radical homopolymerizations of MBMOU and MCMOU for $24 \mathrm{~h}$ at $60^{\circ} \mathrm{C}^{\mathrm{a}}$

\begin{tabular}{|c|c|c|c|c|c|}
\hline Run & Monomer & $\begin{array}{l}\text { Polym. } \\
\frac{\text { Solvent }}{\mathrm{mL}}\end{array}$ & $\frac{\text { Yield }^{b}}{\%}$ & $\frac{\eta^{\mathrm{c}}}{\mathrm{dL} \mathrm{g}^{-1}}$ & $\frac{[\alpha]_{435}^{25} \mathrm{~d}}{\operatorname{deg} .}$ \\
\hline 1 & MBMOU & Tol.(6) & 58.8 & $N D$ & -13.5 \\
\hline 2 & MBMOU & THF(2) & 70.6 & $N D$ & -12.9 \\
\hline 3 & MBMOU & $\operatorname{DMF}(2)$ & 46.6 & 0.37 & -11.6 \\
\hline 4 & MBMOU & $\mathrm{CHCl}_{3}(2)$ & 35.2 & 0.59 & -10.9 \\
\hline 5 & MCMOU & THF(2) & 72.0 & 0.36 & 30.8 \\
\hline 6 & MCMOU & THF(2) & 65.0 & 0.37 & 31.5 \\
\hline 7 & MCMOU & $\operatorname{DMF}(2)$ & trace & & \\
\hline 8 & MCMOU & $\mathrm{CHCl}_{3}(2)$ & 85.7 & 0.44 & 31.4 \\
\hline
\end{tabular}

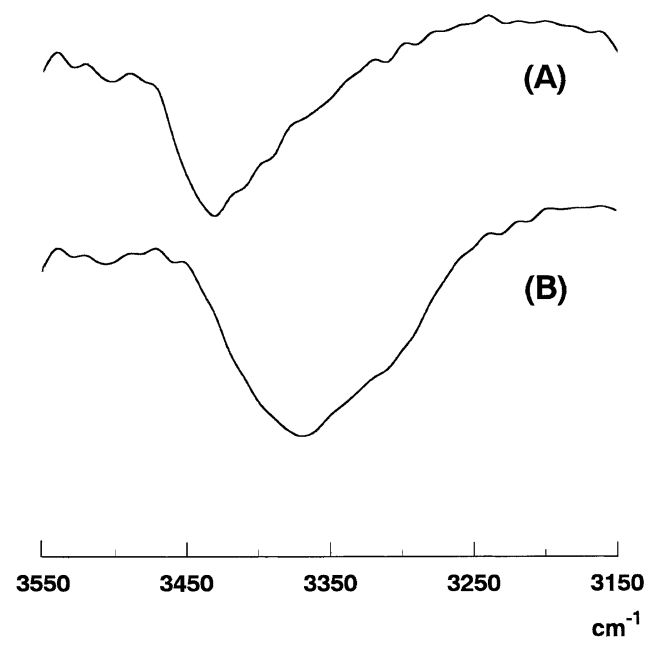

Figure 2. IR spectra for (A) MCMOU and (B) poly(MCMOU) in $\mathrm{CDCl}_{3}$.

tone, and benzene, but soluble in chloroform and DMF. Specific optical rotations $\left([\alpha]_{435}^{25}\right)$ of poly(MBMOU) and poly(MCMOU) were $-10.9^{\circ}$ to $-13.5^{\circ}$ and $30.8^{\circ}$ to 31.5 , respectively, indicating that chiroptical properties of the polymers were scarcely influenced by the polymerization solvents. Figure 1 shows ${ }^{1} \mathrm{H}$ NMR spectra of MCMOU and poly(MCMOU). The peaks assigned to vinyl $\left(\mathrm{CH}_{2}=\mathrm{C}<\right)$ group at $6.12 \mathrm{ppm}, 5.58 \mathrm{ppm}$ disappeared, and the peak due to urea (-NHCONH-) group at $4.84 \mathrm{ppm}$ became broad and sifted at about $5.60 \mathrm{ppm}$ after polymerization, suggesting that the radical polymerization completely proceeded. IR spectra for MCMOU (A) and poly(MCMOU) (B) determined in chloroform are shown in Figure 2. MCMOU exhibited broad absorptions due to stretching vibration of $\mathrm{N}-\mathrm{H}$ at 3320 to $3480 \mathrm{~cm}^{-1}$ having a top peak at $3440 \mathrm{~cm}^{-1}$. Poly(MCMOU) showed broad peak at 3240 to $3460 \mathrm{~cm}^{-1}$ having a top peak at $3360 \mathrm{~cm}^{-1}$. The top peak for poly(MCMOU) shifted from $3440 \mathrm{~cm}^{-1}$ to $3360 \mathrm{~cm}^{-1}$. Thus poly(MCMOU) may have hydrogen

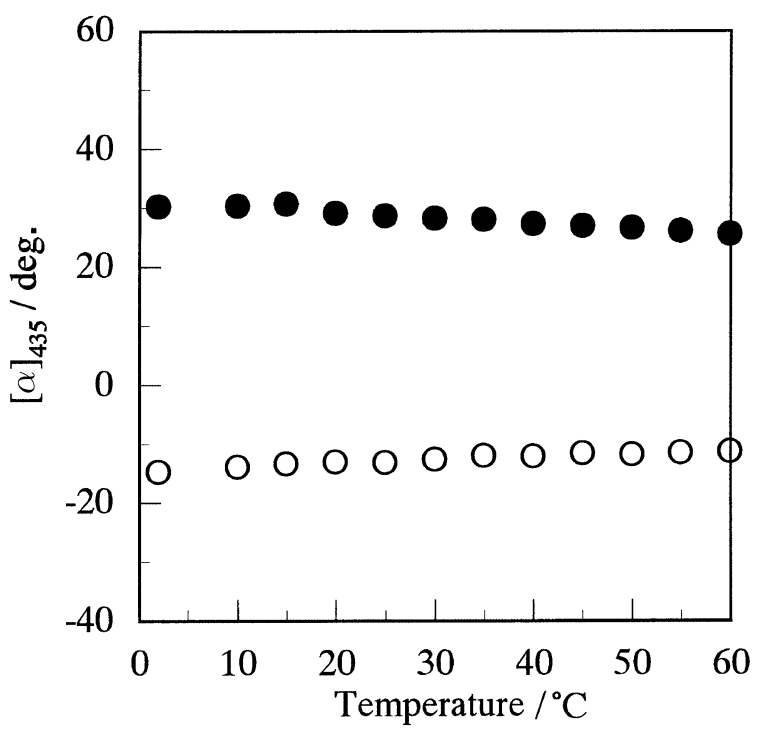

Figure 3. Dependence of specific optical rotation on temperature in DMF ( $\left.c=1.0 \mathrm{~g} \mathrm{dL}^{-1}\right) ;(\bigcirc)$ poly(MBMOU) and ( poly(MCMOU).

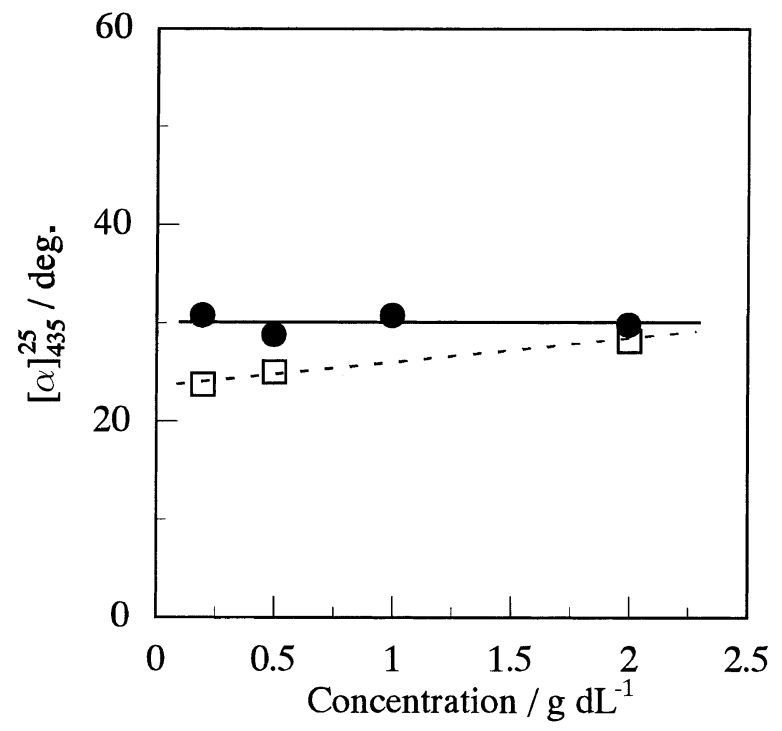

Figure 4. Relationships between specific optical rotation and concentration $\left(\mathrm{g} \mathrm{dL}^{-1}\right)$ of poly(MCMOU) in $(\mathbf{O}) \mathrm{DMF}$ and $(\square)$ $\mathrm{DMF} /$ trifluoroacetic acid (99.8/0.2 $\left.2_{\text {volume }}\right)$.

bonds caused by urea segments.

Specific optical rotations of poly(MBMOU) and poly(MCMOU) were not almost changed by measurement temperature in DMF, as shown in Figure 3. For poly(RMOC) bearing urethane branches in previous work, ${ }^{7,8}$ the absolute values of the specific optical rotations in benzene increased linearly with a decrease of temperature due to change in conformation based on hydrogen bonds between urethane branches. Figure 4 shows relationships between specific optical rotations and the concentration of poly(MCMOU) in DMF and DMF/trifluoroacetic acid (TFA) (99.8/0.2 $\left.2_{\text {volume }}\right)$. The specific optical rotations of poly(MCMOU) were not changed by the concentration in DMF, but changed in 
Table II. Radical Copolymerizations of MBMOU(M $\left(\mathrm{M}_{1}\right)$ and $\operatorname{MCMOU}\left(\mathrm{M}_{1}\right)$ with $\mathrm{ST}\left(\mathrm{M}_{2}\right)$ or BMA $\left(\mathrm{M}_{2}\right)$ in $\mathrm{THF}(2 \mathrm{~mL})$ at $60^{\circ} \mathrm{C}^{\mathrm{a}}$

\begin{tabular}{|c|c|c|c|c|c|c|c|c|c|}
\hline \multirow[t]{2}{*}{ Run } & \multirow[t]{2}{*}{$\mathrm{M}_{1}$} & \multirow[t]{2}{*}{$\mathrm{M}_{2}$} & \multirow{2}{*}{$\begin{array}{c}\mathrm{M}_{1} \text { in } \\
\text { Monomer } \\
\mathrm{mol} \%\end{array}$} & \multirow{2}{*}{$\begin{array}{l}\text { Polym. } \\
\text { Time } \\
\mathrm{h}\end{array}$} & \multirow{2}{*}{$\frac{\text { Yield }^{\mathrm{b}}}{\%}$} & \multicolumn{2}{|c|}{$\begin{array}{c}\mathrm{M}_{1} \text { in } \\
\text { Copolymer }^{\mathrm{c}}\end{array}$} & \multirow{2}{*}{$\frac{\eta^{\mathrm{d}}}{\mathrm{dL}^{-1}}$} & \multirow{2}{*}{$\frac{[\alpha]_{435}^{25 \mathrm{e}}}{\mathrm{deg} .}$} \\
\hline & & & & & & $\overline{\mathrm{mol} \%}$ & $\mathrm{wt} \%$ & & \\
\hline 1 & MBMOU & ST & 5.0 & 24.0 & 31.2 & 10.7 & 23.3 & 0.15 & 2.8 \\
\hline 2 & MBMOU & ST & 10.1 & 18.0 & 13.4 & 27.5 & 49.0 & 0.30 & 3.8 \\
\hline 3 & MBMOU & $\mathrm{ST}$ & 20.2 & 18.0 & 51.4 & 34.6 & 57.3 & 0.36 & 1.9 \\
\hline 4 & MBMOU & ST & 31.0 & 17.5 & 18.0 & 37.5 & 60.3 & 0.32 & -0.1 \\
\hline 5 & MBMOU & ST & 48.3 & 4.0 & 30.6 & 44.1 & 66.0 & 0.40 & -5.6 \\
\hline 6 & MBMOU & ST & 70.0 & 3.6 & 43.0 & 46.8 & 69.1 & 0.38 & -7.6 \\
\hline 7 & MBMOU & ST & 77.9 & 2.3 & 38.0 & 64.8 & 82.3 & 0.37 & -13.3 \\
\hline 8 & MBMOU & BMA & 9.8 & 2.0 & 34.0 & 11.8 & 19.9 & 0.21 & 2.5 \\
\hline 9 & MBMOU & BMA & 20.2 & 1.5 & 31.4 & 23.4 & 36.2 & 0.45 & 1.6 \\
\hline 10 & MBMOU & BMA & 30.1 & 1.3 & 37.0 & 34.6 & 49.5 & 0.55 & 0.1 \\
\hline 11 & MBMOU & BMA & 49.9 & 0.3 & 32.6 & 48.2 & 63.3 & 0.54 & -8.2 \\
\hline 12 & MBMOU & BMA & 69.9 & 1.0 & 32.0 & 53.7 & 68.3 & 0.61 & -12.6 \\
\hline 13 & MBMOU & BMA & 78.5 & 0.5 & 35.0 & 62.8 & 75.8 & 0.88 & -15.5 \\
\hline 14 & MCMOU & ST & 9.6 & 24.0 & 3.4 & 16.6 & 39.0 & $-^{\mathrm{f}}$ & $-{ }^{\mathrm{f}}$ \\
\hline 15 & MCMOU & ST & 19.4 & 24.0 & 30.2 & 31.6 & 59.7 & $--^{\mathrm{f}}$ & $-^{\mathrm{f}}$ \\
\hline 16 & MCMOU & ST & 29.5 & 24.0 & 31.7 & 38.0 & 66.3 & $--^{\mathrm{f}}$ & $--^{\mathrm{f}}$ \\
\hline 17 & MCMOU & ST & 49.6 & 24.0 & 37.1 & 50.8 & 76.8 & $-{ }^{\mathrm{f}}$ & $-{ }^{\mathrm{f}}$ \\
\hline 18 & MCMOU & $\mathrm{ST}$ & 67.4 & 2.0 & 8.0 & 71.2 & 88.8 & $-{ }^{\mathrm{f}}$ & $--^{\mathrm{f}}$ \\
\hline 19 & MCMOU & ST & 81.1 & 1.5 & 37.8 & 89.1 & 96.3 & $-{ }^{\mathrm{f}}$ & $--^{\mathrm{f}}$ \\
\hline 20 & MCMOU & BMA & 5.3 & 5.0 & 31.6 & 9.2 & 19.2 & $-{ }^{f}$ & $-{ }^{\mathrm{f}}$ \\
\hline 21 & MCMOU & BMA & 17.6 & 1.5 & 30.0 & 18.9 & 35.4 & $--^{f}$ & $--^{\mathrm{f}}$ \\
\hline 22 & MCMOU & BMA & 29.3 & 0.5 & 32.0 & 39.8 & 60.7 & $-^{\mathrm{f}}$ & $-^{\mathrm{f}}$ \\
\hline 23 & MCMOU & BMA & 50.8 & 0.5 & 34.4 & 61.8 & 79.1 & $-{ }^{f}$ & $-{ }^{\mathrm{f}}$ \\
\hline 24 & MCMOU & BMA & 69.4 & 0.5 & 34.6 & 71.2 & 85.3 & $-{ }^{f}$ & $-{ }^{\mathrm{f}}$ \\
\hline 25 & MCMOU & BMA & 79.8 & 0.5 & 35.6 & 88.9 & 94.9 & $-{ }^{\mathrm{f}}$ & $-{ }^{\mathrm{f}}$ \\
\hline
\end{tabular}

$N D$, not determined. ${ }^{a}$ Initiator; AIBN, $c=0.03$ mol L ${ }^{-1} ; \mathrm{M}_{1}+\mathrm{M}_{2}=0.5 \mathrm{~g} .{ }^{b}$ Methanol insoluble part. ${ }^{\mathrm{c}}$ Run $1-13$ by ${ }^{1} \mathrm{H}$ NMR; run 14-25 by elemental analysis. ${ }^{\mathrm{d}}$ Measured in DMF at $30^{\circ} \mathrm{C} .{ }^{\mathrm{e}} \mathrm{c}=1.0 \mathrm{~g} \mathrm{dL}^{-1}, l=5 \mathrm{~cm}$, in DMF; error $= \pm 0.3^{\circ}$. ${ }^{\mathrm{f}}$ Insoluble in DMF.

DMF/TFA. Namely, the values of specific optical rotation became slightly lower than those in the absence of TFA acted as an inhibitor for the formation of hydrogen bonds, and increased with an increase of the concentration of the polymer. Thus, poly(MCMOU) may have very strong hydrogen bonds due to urea segments even in DMF, and the changes of specific optical rotation in DMF/TFA may be attributed to change of conformation caused by the hydrogen bonds.

\section{Radical Copolymerizations of MBMOU and MCMOU with ST or BMA}

The results of the radical copolymerizations of MBMOU $\left(\mathrm{M}_{1}\right)$ and MCMOU $\left(\mathrm{M}_{1}\right)$ with ST $\left(\mathrm{M}_{2}\right)$ or BMA $\left(\mathrm{M}_{2}\right)$ using AIBN in toluene at $60^{\circ} \mathrm{C}$ are summarized in Table II. The copolymerizations for MBMOU$\mathrm{M}_{2}$ systems proceeded homogeneously throughout thought for MCMOU-M $\mathrm{M}_{2}$ systems proceeded heterogeneously. Obtained copolymers were colorless powders. Poly(MCMOU-co- $\mathrm{M}_{2}$ )s were insoluble in organic solvents such as THF, chloroform, benzene, acetone, and DMF.
Copolymer composition curves for the polymerizations of MBMOU and MCMOU with ST or BMA are shown in Figure 5. Monomer reactivity ratios $\left(r_{1}, r_{2}\right)$ calculated from the high-conversion method reported by Tüdös et al. ${ }^{19}$ and Alfrey-Price $Q-e$ values ${ }^{20}$ for MBMOU and MCMOU were determined as follows: $r_{1}=0.04, r_{2}=0.22, Q_{1}=0.81, e_{1}=1.35$ in the MBMOU-ST system; $r_{1}=0.20, r_{2}=0.55, Q_{1}=2.25$, $e_{1}=1.77$ in the MBMOU-BMA system; $r_{1}=0.76$, $r_{2}=0.41, Q_{1}=1.09, e_{1}=0.28$ in the MCMOU-ST system; $r_{1}=1.45, r_{2}=0.55, Q_{1}=1.72, e_{1}=0.77$ in the MCMOU-BMA system. $Q_{1}$ and $e_{1}$ values in the $\mathrm{M}_{1}$-ST system were apparently different from those in the $\mathrm{M}_{1}$-BMA system. The reason may result from no consideration of steric effect in the Alfrey-Price $Q$ and $e$ theory. It seems that MBMOU and MCMOU have relatively high steric hindrance because of a large substituent group such as methylbenzyl and phenylalanine ethyl ester groups.

Figure 6 shows relationships between specific optical rotations and content (wt\%) of the monomeric unit of MBMOU in poly(MBMOU-co-M $\left.\mathrm{M}_{2}\right) \mathrm{s}$. Interestingly, 

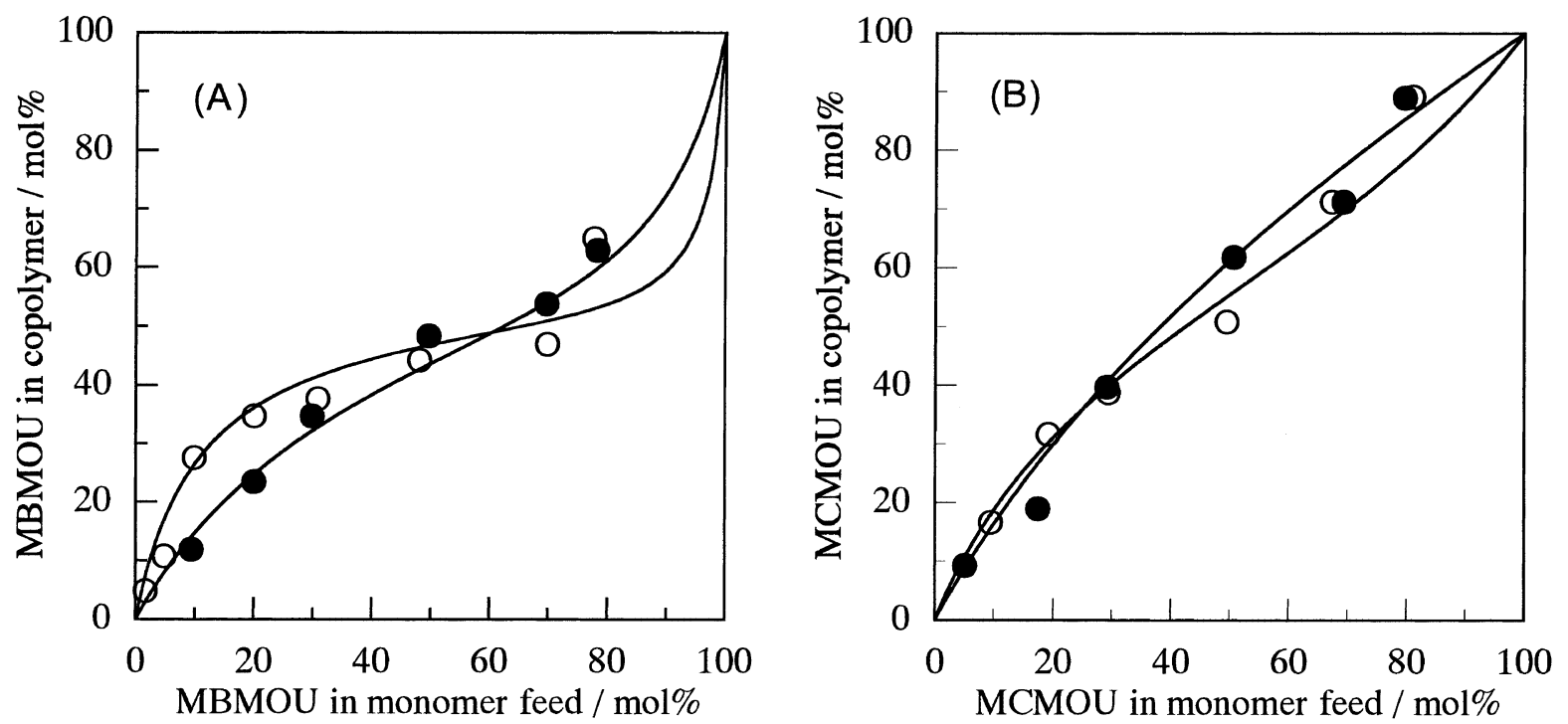

Figure 5. Copolymer composition curves for (A) poly(MBMOU-co- $\left.\mathrm{M}_{2}\right)$ and (B) poly $\left(\mathrm{MCMOU}-c o-\mathrm{M}_{2}\right) ; \mathrm{M}_{2}=(\bigcirc) \mathrm{ST}$ and $(\bullet) \mathrm{BMA}$.

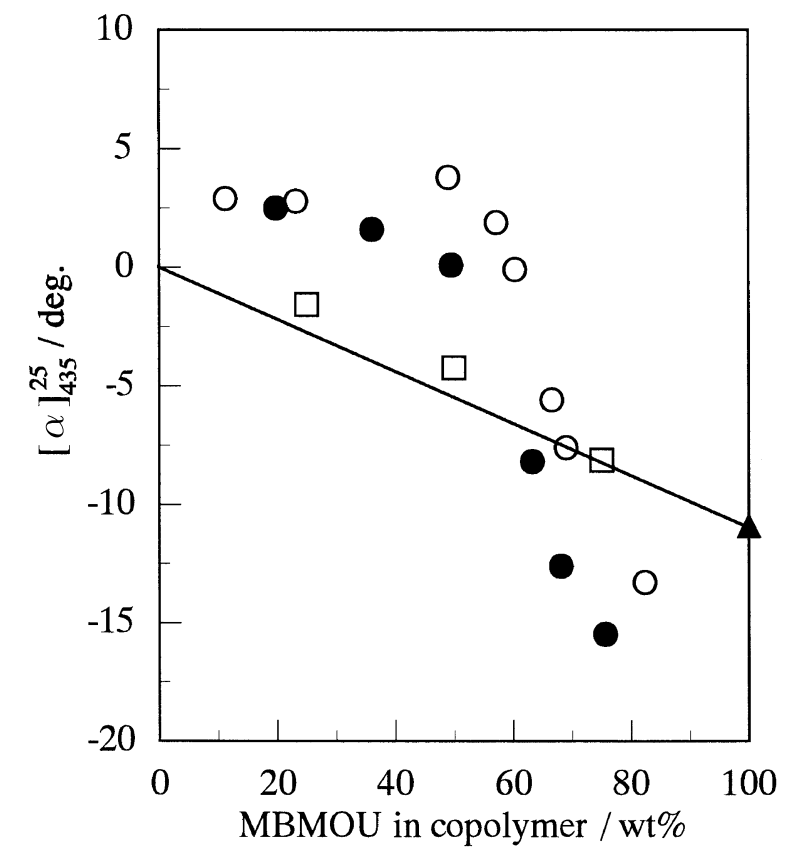

Figure 6. Relationships between specific optical rotation and content $(w t \%)$ of the monomeric unit of MBMOU in copolymer; (O) poly(MBMOU-co-ST)s, ( ) poly(MBMOU-co-BMA)s, $(\boldsymbol{\Delta})$ poly(MBMOU), and ( $\square$ ) mixtures of poly(MBMOU) and poly(ST).

the specific optical rotations of the copolymers changed from positive to negative with an increase of the content of MBMOU monomeric units. A line connecting $0^{\circ}$ with $[\alpha]_{435}^{25}\left(-10.9^{\circ}\right)$ of poly(MBMOU) refers to the relationship between the specific optical rotations and contents $(\mathrm{wt} \%)$ of the monomeric unit in a mixture of poly(MBMOU) and poly(ST) [or poly(BMA)]. In Figure 6, the specific optical rotations of poly(MBMOU$\left.c o-\mathrm{M}_{2}\right) \mathrm{s}$ showed a large deviation from the line, indicating that the chiroptical properties of the copolymers depend strongly on co-units.
Figure 7 shows dependence of specific optical rotations of poly(MBMOU-co- $\mathrm{M}_{2}$ )s on a diad sequence $\left(P_{2}\left[m_{1} m_{2}\right]\right)^{21,22}$ and average sequence length of MBMOU units $\left(l_{1}\right)^{23} . P_{2}\left[m_{1} m_{2}\right]$ indicates probability of a $\mathrm{M}_{1}-M_{2}$ diad sequence. $P_{2}\left[m_{1} m_{2}\right]$ was derived as follows:

$$
\begin{aligned}
& P_{1}\left[m_{1}\right]+P_{1}\left[m_{2}\right]=1 \\
& P_{2}\left[m_{1} m_{2}\right]=P_{1}\left[m_{1}\right] P\left(m_{1} m_{2}\right) \\
& P\left(m_{1} m_{2}\right)=1 /\left(1+r_{1} X\right)
\end{aligned}
$$

where $P_{1}\left[m_{1}\right]$ and $P_{1}\left[m_{2}\right]$ are molar fractions of the copolymer, $P\left(m_{1} m_{2}\right)$ is given by the monomer molar ratio in the feed $\left(X=\mathrm{M}_{1} / \mathrm{M}_{2}\right)$, and $r_{1}$ in the monomer reactivity ratio of MBMOU. In MBMOUST, specific optical rotations increased with increasing the diad sequence, and the relationships showed good linearity (broken line 1), indicating that chiroptical properties of the polymers were strongly influenced by the MBMOU-ST sequence. On the other hand, such a relationship was not observed for the MBMOUBMA system (broken line 2), suggesting that chiroptical properties of the copolymers were influenced by both the MBMOU-BMA diad sequence and the average sequence length of MBMOU units in poly(MBMOUco-BMA)s, as shown in Figure 7B, broken line 4.

Chiral Recognition Ability of Poly(MBMOU) and Poly(MCMOU)

To investigate chiral recognition ability of poly(RMOU), three types of CSPs, poly(MBMOU)bonded-silica gel (CSP-I) and poly(MCMOU)bonded-silica gel (CSP-IIa and CSP-IIb), were prepared according to synthetic routs of Scheme 2. The abilities of the CSPs for chiral recognition of racemates 1-12 (Scheme 3) were examined with HPLC. The 

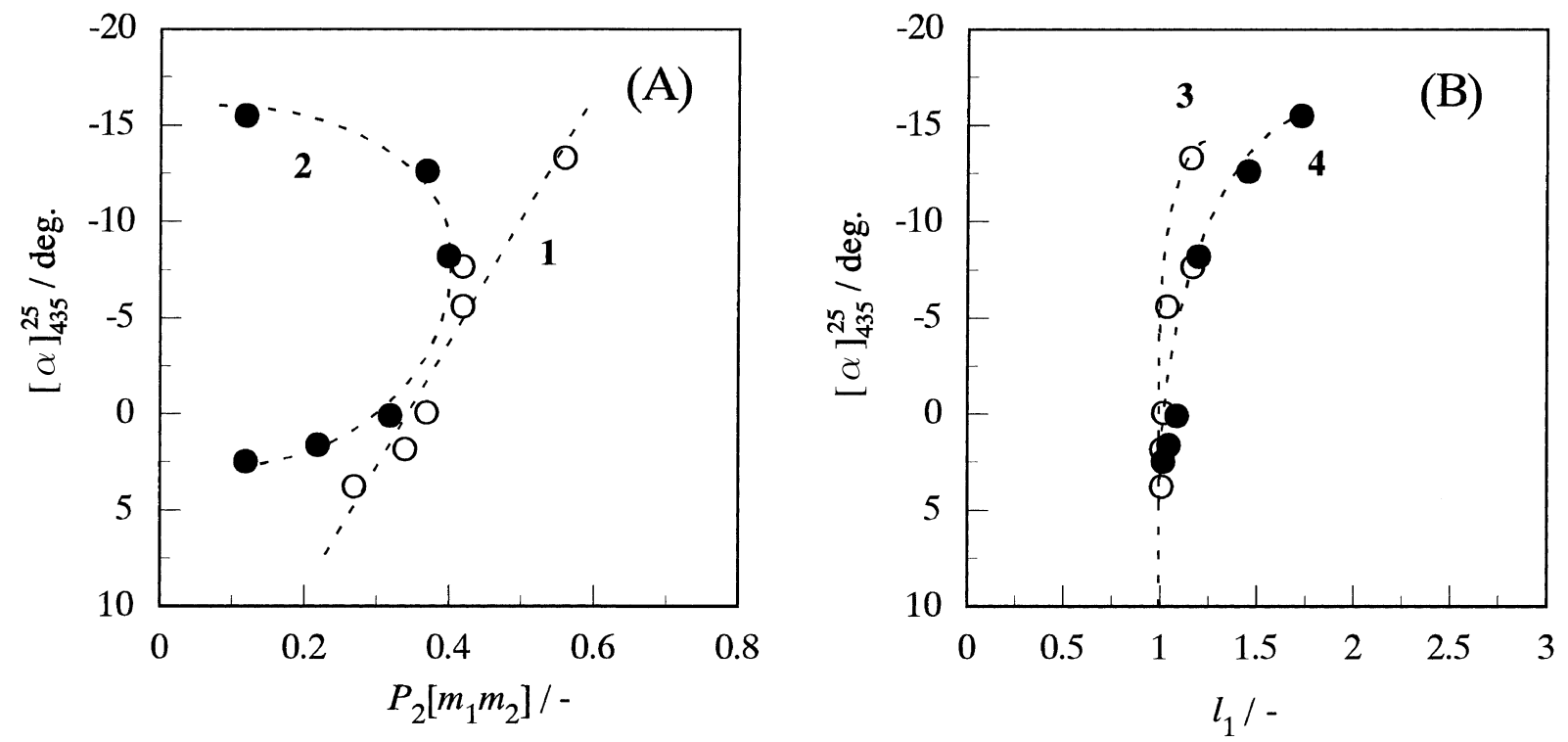

Figure 7. Relationships between specific optical rotation and (A) diad sequence $\left(P_{2}\left[m_{1} m_{2}\right]\right)$ and (B) average sequence length $\left(l_{1}\right)$; $(\bigcirc)$ poly(MBMOU-co-ST)s, (O) poly(MBMOU-co-BMA)s.

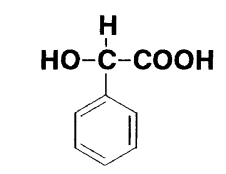

1: Mandelic acid

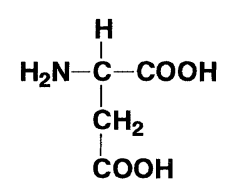

5: Aspartic acid<smiles>CC(O)c1cccc2ccccc12</smiles>

2: Methyl-1-naphthyl

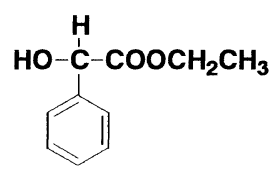

2: Ethyl mandelate

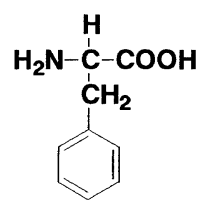

6: Phenyl alanine<smiles>CC(O)c1ccc2ccccc2c1</smiles>

10: Methyl-2-naphthyl alcohol

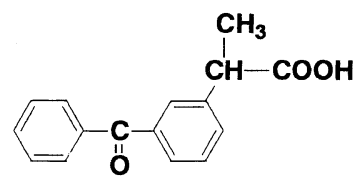

3: Ketoprofen

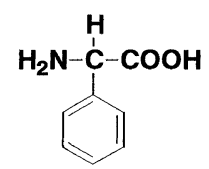

7: Phenyl glycine

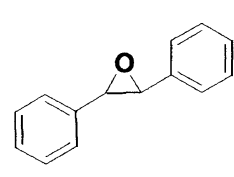

11: trans-Stilbene oxide

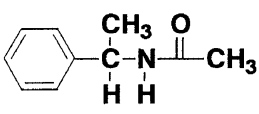

4: $N$-Acetyl-1-phenyl ethyl amine

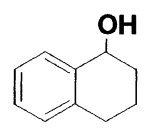

8: 1, 2, 3, 4-Tetrahydro1-naphthyl alcohol

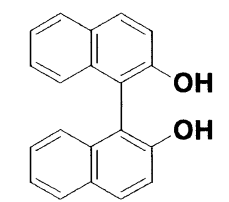

12: 1, 1'-Bi-2-naphthyl alcohol

Scheme 3.

CSPs did not resolve all racemates shown in Scheme 3 in normal phase such as 2-propanol $/ n$-hexane, but resolved racemates 1-4 in reversed phase such as methanol/water. The results are summarized in Table III, and typical chromatogram is shown in Figure 8. In previous work, ${ }^{8}$ the CSPs with poly(RMOC) bearing urethane bonds and $N, N$-dibenzylamino groups could resolve racemates 1-3, histidine, and aspartic acid. As shown in Table III, CSP-I can resolve a racemate 2 , and CSP-IIa can resolve racemates 1-4, though CSP-IIb cannot resolve all racemates. This difference in chiral resolution ability between CSP-IIa and CSP-IIb indicates that the chiral resolution ability may be attributed not only to the urea moieties and chiral pendant groups such as methylbenzyl and phenylalanine methyl ester groups in monomeric units, but to higher-ordered structures of the polymer.

\section{CONCLUSION}

1. Two types of new chiral methacrylates bearing an urea moiety, MBMOU and MCMOU, were synthesized from MOI and $S$-(-)-methylbenzyl amine or L$(-)$-phenylalanine methyl ester.

2. Radical homopolymerizations of MBMOU and MCMOU were carried out in various solvents to obtain 
Table III. Chromatographic resolution of racemates 1-4 on CSP-I, CSP-IIa, and CSP-IIb ${ }^{\mathrm{a}}$

\begin{tabular}{|c|c|c|c|c|c|c|c|c|c|c|c|c|}
\hline \multirow{2}{*}{ Racemates } & \multicolumn{4}{|c|}{ CSP-I } & \multicolumn{4}{|c|}{ CSP-IIa } & \multicolumn{4}{|c|}{ CSP-IIb } \\
\hline & $\overline{k_{1}{ }^{\prime} \mathrm{b}}$ & $k_{2}{ }^{\prime b}$ & $\alpha^{\mathrm{c}}$ & $\overline{R_{\mathrm{S}}}$ & $\overline{k_{1}^{\prime}}$ & $k_{2}^{\prime}$ & $\alpha$ & $\overline{R_{\mathrm{s}}}$ & $\overline{k_{1}^{\prime}}$ & $k_{2}^{\prime}$ & $\alpha$ & $\overline{R_{\mathrm{s}}}$ \\
\hline 1 & 5.3 & 5.3 & 1.0 & & $1.9^{\mathrm{e}}$ & 2.5 & 1.32 & 0.52 & 5.3 & 5.3 & 1.0 & \\
\hline 2 & 4.8 & 5.7 & 1.19 & 0.64 & 4.1 & 4.9 & 1.20 & 0.35 & 5.2 & 5.2 & 1.0 & \\
\hline 3 & $1.7^{\mathrm{d}}$ & 1.7 & 1.0 & & 6.3 & 7.1 & 1.13 & 0.41 & 5.9 & 5.9 & 1.0 & \\
\hline 4 & $1.6^{\mathrm{d}, \mathrm{e}}$ & 1.6 & 1.0 & & 4.2 & 5.2 & 1.24 & 0.67 & $N D$ & & & \\
\hline
\end{tabular}

$N D$, not determined. a Column size, $150 \mathrm{~mm} \times 2 \mathrm{~mm}$; CSP-I, poly(MBMOU)-bonded-silica gel; CSP-IIa and CSPIIb poly(MCMOU)-bonded-silica gel; mobile phase, methanol $/$ water $=7 / 3$; flow, $0.05 \mathrm{~mL} \mathrm{~min}{ }^{-1}$. ${ }^{\mathrm{b}}$ Capacity factor of enantiomer eluting first $\left(k_{1}{ }^{\prime}\right)$ and second $\left(k_{2}{ }^{\prime}\right)=$ (retention time of enantiomer-void time of column)/(retention time of 1,3,5-t-butylbenzene). ${ }^{\mathrm{c} S e p a r a t i o n}$ factor $=k_{2}{ }^{\prime} / k_{1}{ }^{\prime}$. ${ }^{\mathrm{d}}$ Flow $=0.1 \mathrm{~mL} \mathrm{~min}^{-1}$. ${ }^{\mathrm{e}}$ Mobile phase, methanol $/$ water $=9 / 1$.
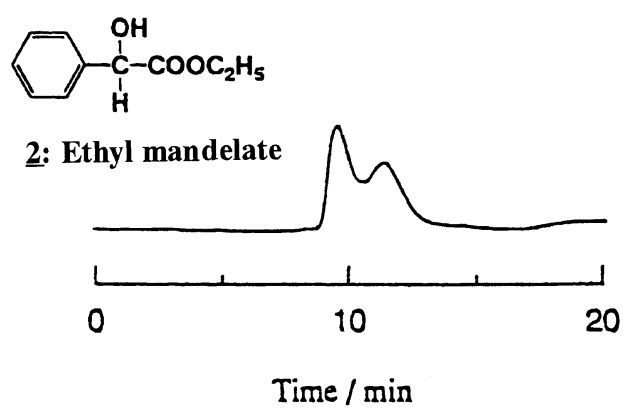

Figure 8. Typical HPLC chromatogram of chiral resolution with CSP-I in methanol/water (7/3) as mobile phases; column, 150

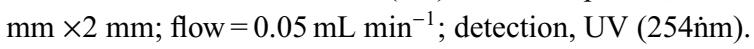

the corresponding polymers whose chiroptical property was not affected by temperature since the polymers had very strong hydrogen bonds based on the urea moieties.

3. From the results of the copolymerizations of MBMOU and MCMOU with ST or BMA, monomer reactivity ratios, $Q$, and $e$ values were determined. Chiroptical properties of poly(MBMOU-co-ST)s and poly(MBMOU-co-BMA)s were significantly influenced by $c o$-units.

4. CSPs prepared from silica gel and poly(MBMOU) or poly(MCMOU) resolved racemates 1-4 by HPLC. The abilities of CSPs for chiral recognition may be attributed to higher-ordered structures of the polymer.

Acknowledgment. This work was carried out under the Research Program for Special Promotion of the Venture Business Laboratory, Yamaguchi University. The authors thankful to Showa Denko Co. Ltd. for supplying the MOI.

\section{REFERENCES}

1. S. Matsuhiro, Konbatekku, 5, 8 (1997).

2. a) H. Kamogawa, H. Kohno, and R. Kitagawa, J. Polym. Sci., Part A: Polym. Chem., 27, 487 (1989).

b) C. Decker and K. Moussa, Eur. Polym. J., 27, 881 (1991).

c) I. Francis, S. Arjen, C. Israel, and S. Johannes, J. Polym. Sci., Part A: Polym. Chem., 31, 239 (1993).

3. a) H. Albrecht and W. Wunderlich, Angew. Makromol. Chem., 145/146, 89 (1986). b) S. Savaskan and B. Hazer, Angew. Makromol. Chem., 239, 13 (1996).

c) N. Monzner, U. K. Fischer, T. Volkel, and V. Rheinberger, Angew. Makromol. Chem., 245, 155 (1997).

4. T. Oishi, Y.-K. Lee, A. Nakagawa, K. Onimura, and H. Tsutsumi, Polym. J., 33, 81 (2001).

5. C. H. Bamford, K. G. Al-Lamee, I. P. Middleton, J. Paprotny, and R. Carr, Bull. Soc. Chim. Belg., 99, 919 (1990).

6. Y. Kimitsuka, K. Iwata, H. Suzuki, Jpn. Kokai Tokkyo Koho, JP 6-308108 (Nov. 4, 1994).

7. Y. K. Lee, K. Onimura, H. Tsutsumi, and T. Oishi, J. Polym. Sci., Part A: Polym. Chem., 38, 4315 (2000).

8. Y. K. Lee, K. Onimura, H. Tsutsumi, and T. Oishi, Polym. J., 32, 1007 (2000).

9. Y. K. Lee, K. Onimura, H. Tsutsumi, and T. Oishi, Polym. J., 33, 411 (2001).

10. S. G. Allenmark, "Chromatographic Enantioseparation", Ellis Horwood Limited., Chichester, UK, 1988.

11. For example, Y. Okamoto, CHEMTECH, 176 (1987).

12. J. H. Liu and F. J. Tsai, J. Appl. Polym. Sci., 72, 677 (1999).

13. Y. Tamai, P. Qian, K. Matsunaga, and S. Miyano, Bull. Chem. Soc. Jpn., 65, 817 (1992).

14. a) G. Blaschke, Angew. Chem. Int. Ed. Eng., 19, 13 (1980). b) G. Blaschke, W. Broker, and E. Frankel, Angew. Chem. Int. Ed. Eng., 25, 830 (1986).

15. D. Arlt, B. Bomer, R. Grosser, and W. Lange, Angew. Chem. Int. Ed. Eng., 30, 1662 (1991).

16. T. Otsu and M. Kinoshita, "Koubunshigousei Jikkenhou", Kagaku-doujin Publishing Co., Ltd., Kyoto, 1972, pp 69-91.

17. N. Izumiya and T. Kato, "Pepuchidogousei no Kiso to Jikken”, Maruzen, Tokyo, 1985, pp 50-51.

18. Y. Okamoto, E. Yashima, M. Ishihara, and K. Hatada, Bull. Chem. Soc. Jpn., 61, 255 (1988).

19. F. Tüdös, T. Kelen, T. Foldes-Berezsnich, and B. Turcsanyi, J. Macromol. Sci. Chem., A10, 1513 (1976).

The monomer reactivity rations were determined by the method 6 described in this paper.

20. T. Alfrey, Jr., and C. C. Price, J. Polym. Sci., 2, 101 (1947).

21. H. J. Harwood and W. M. Ritchey, J. Polym. Sci., Polym. Lett. Ed., 2, 601 (1964).

22. M. Kurokawa, H. Yamaguchi, and Y. Minoura, J. Polym. Sci., Chem. Ed., 17, 2241 (1979).

23. R. N. Majumdar, C. Carlini, and C. Bertucci, Makromol. Chem., 183, 2047 (1982). 